\title{
A new method to determine reasonable well pattern density in low- permeability gas reservoirs
}

\author{
Tianjin Zhang ${ }^{1} \cdot$ Zhisheng Zhang $^{2} \cdot$ Chunsheng $\mathrm{Li}^{3} \cdot \mathrm{Hu} \mathrm{Xia}^{4} \cdot \mathrm{Hailong} \mathrm{Liu}^{4}$
}

Received: 26 September 2018 / Accepted: 7 February 2019 / Published online: 19 February 2019

(c) The Author(s) 2019

\begin{abstract}
The productivity evaluation of gas reservoirs is used to determine the optimal number of well pattern, which is an important part of the preparation of gas reservoir development plan. Using integral transformation and asymptotic analyses to solve the pseudo steady-state flow model in closed rectangular gas reservoir of constant thickness, analytic solution of pressure distribution of eccentric well can be obtained. This paper presents mathematical model of multiple wells producing from a closed gas reservoir by applying the principle of pressure superposition. The pseudo steady-state dimensionless production index is introduced to solve the multiple well mathematical models under the constant pressure, and the number of production wells and cumulative production in different production interval are obtained. The results of the calculation shows that the curve of the cumulative production and economic benefits have a maximum value when the producing time, gas price, and drilling costs are given, so it can determine the optimal number of wells and provide the basis for making gas reservoir development plan.
\end{abstract}

Keywords Low-permeability gas reservoirs $\cdot$ Pressure superposition principle $\cdot$ Dimensionless production index $\cdot$ Well pattern density $\cdot$ Pressure distribution

\section{Introduction}

At present, the supply and demand of oil and gas resources are increasing. Since 2014, the international oil price has fallen. Most of the domestic oil and gas field development have entered a stage of high water cut, and the development effect is not satisfactory. It is necessary to reorganize the well pattern or design infilling wells to enhance oil recovery (Bowers 1981). Due to the existence of non-linear seepage mechanism such as pressure-sensitive effect, the well spacing between the injection well and the production well can not be too large in low-permeability reservoirs, and generally need to do well pattern infilling (Zhang Fenglian and Yuting 2008). Well pattern

$\mathrm{Hu}$ Xia

huhaixia0@126.com

1 College of Petrol and Environmental Engineering, Yan'an University, Yan'an 716000, China

2 Yan Chang Petroleum. Co. Ltd., Xingzichuan Oilfield, Yan' an 717400, China

3 Yan Chang Petroleum. Co. Ltd., Dingbian Oilfield, Yulin 718600, China

4 China University of Geosciences, Beijing 100083, China infilling technology can effectively delay the decline of oil and gas well production. Without taking economic effectiveness into consideration, it is considered that the smaller the well pattern density is, the higher the oil recovery is. However, for each additional infilling well, the investment cost increases and the economic effectiveness decreases. It is not that the smaller the well pattern density is, the better the development benefit is. Choosing a reasonable well pattern density for oil and gas field development is the key to enhance oil recovery and reduce investment costs. How to determine a reasonable well pattern density and obtain maximum economic benefits quickly and accurately becomes an urgent problem to be solved in the development of the oil and gas field.

Since the 1930s, many scholars have begun to study the density of well patterns, and they also have made great progress. There are many methods to calculate the density of well patterns, such as reasonable oil recovery method (Hongbing and Yang 2013; Cunyou and Haibo 2010; Hongge 2014; Jinshan 2013; Song et al. 2014), single well productivity method (Xie and Hongwei 2010; Mengkun et al. 2012; Awotunde 2014; Krisanne et al. 2011), water drive control degree method (Changmin and Xiaoqing 2012; Quanlin et al. 2012), numerical simulation method (John 2010, 2011), and physical simulation method (Lalehrokh 
and Bouma 2014; Yikun and Liang 2010). The above methods mainly have the following shortcomings:

1. The seepage model uses special functions.

2. The derivation and calculation are cumbersome.

3. The well pattern evaluation method is more suitable for the small well group, which is inconsistent with the actual well pattern.

4. The various modeling methods are relatively independent, and the formula expansion is poor.

Therefore, this paper starts from the governing equation of seepage mechanics, and considers the pressure-sensitive effect of low-permeability gas reservoir, and introduces the dimensionless transformation to transform the nonlinear seepage equation into an easy seepage equation. The mathematical model of the unstable seepage flow is solved by means of dimensionless transformation, Laplace transformation, Fourier cosine transformation, and separation variable method. Then, the asymptotic analysis method is used to give the single well pressure approximate solution at any time and any position. Finally, the superposition principle is used to solve the multi-well pressure. The solution model to pressure and average pressure is obtained. The net present value method is used to establish the relationship function between the number of production wells and economic benefits. The extreme value method of multivariate is used to establish the model of well pattern density.

\section{Single well model}

\section{The constant flow model}

The physical model of low-permeability rectangular gas reservoirs is shown in Fig. 1. To simplify the physical model, the assumptions are made as the followings:

1. The fluid in the reservoir is slightly compressible.

2. The gas reservoir is heterogeneous, but the permeability in the $x$ and $y$ direction at the same position is the same.

3 . The flow of fluid in the gas reservoir has a pressuresensitive effect.

4. The gas density is constant.

The length, width, and height of the rectangular gas reservoir are $x_{\mathrm{e}}, y_{\mathrm{e}}, h$, and the porosity is $\varphi$. The initial viscosity is $\mu_{\mathrm{gi}}$. The fluid flow is unstable in the rectangular gas reservoir. The rectangular coordinate system is established, and one well is located at $\left(x_{\mathrm{w}}, y_{\mathrm{w}}\right)$. The production well is produced at a flow rate $q_{\mathrm{sc}}$. The gas seepage control equation considering the pressure-sensitive effect is (Jian et al. 2013; Wu 2012):

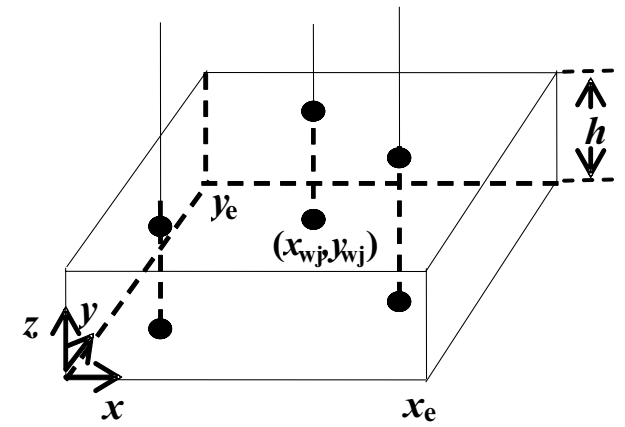

Fig. 1 The physical model of gas reservoir

$\frac{\partial\left[\rho \frac{K_{\mathrm{gi}} \mathrm{e}^{-\alpha\left(p_{i}-p\right)}}{\mu_{\mathrm{gi}}} \frac{\partial p}{\partial x}\right]}{\partial x}+\frac{\partial\left[\rho \frac{K_{\mathrm{gi}} \mathrm{e}^{-\alpha\left(p_{i}-p\right)}}{\mu_{\mathrm{gi}}} \frac{\partial p}{\partial y}\right]}{\partial y}=\frac{\partial(\rho \varphi)}{\partial t}$,

where $k_{\mathrm{gi}}$ is the original permeability of the reservoir, $\mu \mathrm{m}^{2} . \rho$ is the reservoir fluid density, $\mathrm{g} / \mathrm{cm}^{3} . t$ is the producing time, h. $\alpha$ is the stress sensitivity coefficient, $\mathrm{MPa}^{-1} \cdot \mu_{\mathrm{gi}}$ is the gas viscosity under the original reservoir pressure, $\mathrm{mPa}$ s. $p_{\mathrm{i}}$ is the original reservoir pressure, MPa. $p$ is the reservoir fluid pressure, MPa.

Gas properties (such as viscosity, compressibility, compression factor, etc.) are related to gas pressure, which makes the Eq. (1) a nonlinear equation.

Define the pseudo-pressure function:

$p_{\mathrm{p}}(p)=2 \int_{0}^{p} \frac{\mu_{\mathrm{gi}} Z_{\mathrm{i}}}{p_{\mathrm{i}}} \frac{\varepsilon \mathrm{e}^{-\alpha\left(p_{\mathrm{i}}-\varepsilon\right)}}{\mu_{\mathrm{g}}(\varepsilon) Z(\varepsilon)} \mathrm{d} \varepsilon$

where $Z_{\mathrm{i}}$ is the gas compression factor at the original reservoir pressure. $\mu_{\mathrm{g}}(\varepsilon)$ is a function of gas viscosity, and it can be expressed by the gas pressure function. $Z(\varepsilon)$ is the function of the gas compression factor, and it can be expressed by the gas pressure function.

Substitute the pseudo-pressure function into Eq. (1), we can get:

$\frac{\partial^{2} p_{\mathrm{p}}}{\partial x^{2}}+\frac{\partial^{2} p_{\mathrm{p}}}{\partial y^{2}}=\frac{1}{\eta\left(p_{\mathrm{p}}\right)} \frac{\partial p_{\mathrm{p}}}{\partial t}$

where $\eta\left(p_{\mathrm{p}}\right)=\frac{K_{\mathrm{gi}}}{\varphi \mu_{\mathrm{g}}\left(p_{\mathrm{p}}\right) c_{\mathrm{g}}\left(p_{\mathrm{p}}\right)}$.

Since $\eta\left(p_{\mathrm{p}}\right)$ is still a function of $p_{\mathrm{p}}(p)$, the Eq. (1) is not completely linearized by introducing the pseudo-pressure function. A lot of research have been done on how to linearize $\eta\left(p_{\mathrm{p}}\right)$. For example, Kale and Mattar use the perturbation method to give the radial flow approximation solution under constant flow condition (Kale and Mattar 2004). Peres and Reynolds use the Boltzmann transformation method 
to study the solution to the vertical well under the infinite atmospheric condition. However, these methods are suitable for self-similarity problems. There are many practical problems of other nonlinear well tests, and it does exist much error to analyze the pressure when using these methods. For the variable flow problem in well test analysis, the Duhamel convolution method is commonly used to solve the equation (Thompson and Reynolds 2009), but $\eta\left(p_{p}\right)$ is treated as a constant and it is mostly used for radial seepage. There are still some shortcomings for conventional two-dimensional seepage. This paper starts with the general 2-D gas reservoir and studies the variable yield and constant yield problems. Through the dimensionless transformation and integral transformation method, the exact solution of vertical well pressure at any position and at any time is obtained.

The dimensionless transformation is a method of converting the seepage equation into a conventional mathematical equation. By dimensionless transformation, the number of comparisons can be greatly reduced, which makes the mathematical physics equation simple, neat, easy to analyze and solve. The following dimensionless transformation is introduced in this paper:

$$
\begin{gathered}
p_{\mathrm{pD}}=\frac{542.87 K_{\mathrm{gi}} h\left[p_{\mathrm{p}}\left(p_{\mathrm{i}}\right)-p_{\mathrm{p}}(p)\right]}{q_{\mathrm{sc}} B_{\mathrm{gi}} \mu_{\mathrm{gi}}}, \quad x_{\mathrm{D}}=\frac{x}{r_{\mathrm{w}}}, \quad x_{\mathrm{eD}}=\frac{x_{\mathrm{e}}}{r_{\mathrm{w}}}, \\
y_{\mathrm{D}}=\frac{y}{r_{\mathrm{w}}}, \quad y_{\mathrm{eD}}=\frac{y_{\mathrm{e}}}{r_{\mathrm{w}}}, \quad t_{\mathrm{D}}=\frac{3.6 K_{\mathrm{gi}} t}{\varphi \mu_{\mathrm{gi}} c_{\mathrm{gi}} r_{\mathrm{w}}^{2}},
\end{gathered}
$$

where $q_{\mathrm{sc}}$ is the production, $\mathrm{m}^{3} / \mathrm{d}$. $B_{\mathrm{gi}}$ is the gas volume coefficient under the original reservoir pressure. $c_{\mathrm{gi}}$ is the gas compression coefficient under the original reservoir pressure, $\mathrm{MPa}^{-1} \cdot r_{\mathrm{w}}$ is the radius of the production wellbore, $\mathrm{m}$. $p_{\mathrm{p}}(p)$ is the pseudo-pressure function, MPa.

Through the dimensionless transformation, the Eq. (2) can be written as follows:

$\frac{\partial^{2} p_{\mathrm{pD}}}{\partial x_{\mathrm{D}}^{2}}+\frac{\partial^{2} p_{\mathrm{pD}}}{\partial y_{\mathrm{D}}^{2}}=\frac{\partial p_{\mathrm{pD}}}{\partial t_{\mathrm{D}}}$.

Initial conditions:

$$
\begin{aligned}
p_{\mathrm{pD}}\left(x_{\mathrm{D}}, y_{\mathrm{D}}, 0\right) & =0, \lim _{r_{\mathrm{D}} \rightarrow 1}\left[r_{\mathrm{D}} \frac{\partial p_{\mathrm{pD}}\left(x_{\mathrm{D}}, y_{\mathrm{D}}, t_{\mathrm{D}}\right)}{\partial r_{\mathrm{D}}}\right] \\
=-1, \quad r_{\mathrm{D}}^{2} & =\left(x_{\mathrm{D}}-x_{\mathrm{wD}}\right)^{2}+\left(y_{\mathrm{D}}-y_{\mathrm{wD}}\right)^{2} .
\end{aligned}
$$

Boundary conditions:

$$
\begin{aligned}
& \frac{\partial p_{\mathrm{pD}}\left(0, y_{\mathrm{D}}, t_{\mathrm{D}}\right)}{\partial x_{\mathrm{D}}}=0, \frac{\partial p_{\mathrm{pD}}\left(x_{\mathrm{eD}}, y_{\mathrm{D}}, t_{\mathrm{D}}\right)}{\partial x_{\mathrm{D}}}=0, \\
& \frac{\partial p_{\mathrm{pD}}\left(x_{\mathrm{D}}, 0, t_{\mathrm{D}}\right)}{\partial y_{\mathrm{D}}}=0, \frac{\partial p_{\mathrm{pD}}\left(x_{\mathrm{D}}, y_{\mathrm{eD}}, t_{\mathrm{D}}\right)}{\partial y_{\mathrm{D}}}=0,
\end{aligned}
$$

Using Laplace transformation, the Eq. (3) can be written as follows:

$\frac{\partial^{2} \tilde{P}_{\mathrm{pD}}}{\partial x_{\mathrm{D}}^{2}}+\frac{\partial^{2} \tilde{P}_{\mathrm{pD}}}{\partial x_{\mathrm{y}}^{2}}=s \tilde{P}_{\mathrm{pD}}$.

Using Fourier cosine transformation of $x_{\mathrm{D}}$ and $y_{\mathrm{D}}$, the Eq. (7) can be written as follows:

$\overline{\tilde{\tilde{P}}}_{\mathrm{pD}}\left(u_{\mathrm{n}}, v_{\mathrm{m}}, s\right)=\frac{\cos \left(u_{\mathrm{n}} x_{\mathrm{eD}}\right) \cos \left(v_{\mathrm{m}} y_{\mathrm{eD}}\right)}{s+u_{\mathrm{n}}^{2}+v_{\mathrm{m}}^{2}}$,

where $u_{\mathrm{n}}=\frac{n \pi}{x_{\mathrm{eD}}}, v_{\mathrm{m}}=\frac{m \pi}{y_{\mathrm{eD}}}(m, n$ is natural number $)$.

Using Fourier cosine inverse transformation of $u_{\mathrm{n}}$ and $v_{\mathrm{m}}$, the Eq. (8) can be written as follows:

$$
\begin{aligned}
\tilde{P}_{\mathrm{pD}}\left(x_{\mathrm{D}}, y_{\mathrm{D}}, s\right)= & \sum_{n=1}^{\infty} \frac{2 \cos \left(u_{\mathrm{n}} x_{\mathrm{D}}\right) \cos \left(u_{\mathrm{n}} x_{\mathrm{eD}}\right)}{s+u_{\mathrm{n}}^{2}} \\
& \times \sum_{m=1}^{\infty} \frac{2 \cos \left(v_{\mathrm{m}} y_{\mathrm{D}}\right) \cos \left(v_{\mathrm{m}} y_{\mathrm{eD}}\right)}{s+u_{\mathrm{n}}^{2}+v_{\mathrm{m}}^{2}} .
\end{aligned}
$$

By introducing the equations:

$\sum_{k=1}^{\infty} \frac{\cos k x}{k^{2}+a^{2}}=\frac{\pi}{2 a} \frac{\cosh a(\pi-x)}{\sinh a \pi}-\frac{1}{2 a^{2}}$,

The Eq. (9) can be written as follows:

$$
\begin{aligned}
s \tilde{P}_{\mathrm{pD}}\left(x_{\mathrm{D}}, y_{\mathrm{D}}, s\right)= & \frac{\pi}{x_{\mathrm{eD}}} \frac{\cosh \varepsilon_{0}\left[y_{\mathrm{eD}}-\left|y_{\mathrm{D}} \pm y_{\mathrm{wD}}\right|\right]}{\varepsilon_{0} \sinh y_{e D} \varepsilon_{0}} \\
& +\frac{2 \pi}{x_{\mathrm{eD}}} \times \sum_{n=1}^{\infty} \cos \frac{n \pi x_{\mathrm{wD}}}{x_{\mathrm{eD}}} \cos \frac{n \pi x_{\mathrm{D}}}{x_{\mathrm{eD}}} \\
& \times \frac{\cosh \varepsilon_{n}\left(y_{\mathrm{eD}}-\left|y_{\mathrm{D}} \pm y_{\mathrm{wD}}\right|\right)}{\varepsilon_{n} \sinh y_{\mathrm{eD}} \varepsilon_{n}},
\end{aligned}
$$

where $\varepsilon_{n}=\sqrt{s+n^{2} \pi^{2} / x_{\mathrm{eD}}^{2}}$. 
When $t_{\mathrm{D}}$ is large enough, the dimensionless pressure distribution is obtained by asymptotic analysis:

$$
\begin{aligned}
P_{\mathrm{pD}}\left(x_{\mathrm{D}}, y_{\mathrm{D}}, t_{\mathrm{D}}\right)= & \frac{2 \pi t_{\mathrm{D}}}{x_{\mathrm{eD}} y_{\mathrm{eD}}} \\
& +2 \pi \frac{y_{\mathrm{eD}}}{x_{\mathrm{eD}}}\left(\frac{1}{3}-\frac{\left|y_{\mathrm{D}} \pm y_{\mathrm{wD}}\right|}{2 y_{\mathrm{eD}}}+\frac{y_{\mathrm{D}}^{2}+y_{\mathrm{wD}}^{2}}{2 y_{\mathrm{eD}}^{2}}\right) \\
& +2 \sum_{k=1}^{\infty} \frac{1}{k} \frac{\cosh k \pi\left(y_{\mathrm{eD}}-\left|y_{\mathrm{D}} \pm y_{\mathrm{wD}}\right|\right) / x_{\mathrm{eD}}}{\sinh \left(k \pi y_{\mathrm{eD}} / x_{\mathrm{eD}}\right)} \\
& \times \cos \frac{k \pi x_{\mathrm{D}}}{x_{\mathrm{eD}}} \cos \frac{k \pi x_{\mathrm{wD}}}{x_{\mathrm{eD}}}
\end{aligned}
$$

The Eq. (11) can be written in dimensional form:

$$
P_{\mathrm{pi}}-P_{\mathrm{p}}(x, y, t)=\frac{q_{\mathrm{sc}} B_{\mathrm{gi}} \mu_{\mathrm{gi}}}{542.87 k_{\mathrm{g}} h}\left(\frac{2 \pi}{x_{\mathrm{e}} y_{\mathrm{e}}} \frac{k_{\mathrm{g}}}{\varphi c_{\mathrm{gi}} \mu_{\mathrm{gi}}}+F\right),
$$

where influence function $F$ is

$$
\begin{aligned}
F\left[x, y, x_{\mathrm{w}}, y_{\mathrm{w}}, x_{\mathrm{e}}, y_{\mathrm{e}}\right]= & 2 \pi \frac{y_{\mathrm{e}}}{x_{\mathrm{e}}} \times\left(\frac{1}{3}-\frac{\left|y \pm y_{\mathrm{w}}\right|}{2 y_{\mathrm{e}}}+\frac{y^{2}+y_{\mathrm{w}}^{2}}{2 y_{\mathrm{e}}^{2}}\right) \\
& +2 \sum_{k=1}^{\infty} \frac{1}{k} \frac{\cosh k \pi\left(y_{\mathrm{e}}-\left|y \pm y_{\mathrm{w}}\right|\right) / x_{\mathrm{e}}}{\sinh \left(k \pi y_{\mathrm{e}} / x_{\mathrm{e}}\right)} \\
& \times \cos \frac{k \pi x}{x_{\mathrm{e}}} \cos \frac{k \pi x_{\mathrm{w}}}{x_{\mathrm{e}}} .
\end{aligned}
$$

\section{The variable flow model}

When the well production changes, the variable flow model of the low-permeability gas reservoir is obtained, with taking the skin factor into consideration.

$$
\begin{aligned}
P_{\mathrm{pi}} & -P_{\mathrm{p}}(x, y, t)=\frac{B_{\mathrm{gi}} \mu_{\mathrm{gi}}}{542.87 K_{\mathrm{g}} h} \\
\times & {\left[\frac{2 \pi}{x_{\mathrm{e}} y_{\mathrm{e}}} \frac{K_{\mathrm{g}}}{\varphi \mu_{\mathrm{gi}} c_{\mathrm{gi}}} \int_{0}^{t} q_{\mathrm{sc}}(t) \mathrm{d} t+(F+s) q_{\mathrm{sc}}(t)\right] . }
\end{aligned}
$$

According to the conservation of quality, we can get

$$
P_{\mathrm{pi}}-\bar{P}_{\mathrm{p}}=\frac{B_{\mathrm{gi}} \mu_{\mathrm{gi}}}{542.87 K_{\mathrm{g}} h} \frac{2 \pi}{x_{\mathrm{e}} y_{\mathrm{e}}} \frac{K_{\mathrm{g}}}{\varphi \mu_{\mathrm{gi}} c_{\mathrm{gi}}} \int_{0}^{t} q_{\mathrm{sc}}(\tau) \partial \tau .
$$

Eliminate the time term by the combination of Eqs. (14) and (15), and introduce the average pressure, we can get

$\bar{P}_{\mathrm{p}}-P_{\mathrm{p}}(x, y, t)=\frac{\alpha_{1} B_{\mathrm{gi}} \mu_{\mathrm{gi}}}{2 \pi K_{\mathrm{g}} h} q_{\mathrm{sc}}(t) \times\left[s+F\left(x, y, x_{\mathrm{w}}, y_{\mathrm{w}}, x_{\mathrm{e}}, y_{\mathrm{e}}\right)\right]$, where $\alpha_{1}$ is the unit conversion factor, and in the SI unit system (Chen 1988), $\alpha_{1}$ is $1.1574 \times 10^{-2}$.

\section{Multi-well model}

\section{Transient production}

When there are n wells producing at the same time, according to the pressure drop superposition principle [superimpose the Eq. (16)], we can get

$\bar{P}_{\mathrm{p}}-P_{\mathrm{p}}(x, y, t)=\frac{\alpha_{1} B_{\mathrm{gi}} \mu_{\mathrm{gi}}}{2 \pi K_{\mathrm{g}} h} \sum_{j=1}^{n} q_{\mathrm{scj}}(t) \times\left[F_{\mathrm{j}}\left(x, y, x_{\mathrm{wj}}, y_{\mathrm{wj}}, x_{\mathrm{e}}, y_{\mathrm{e}}\right)+s_{\mathrm{j}}\right]$.

Rewrite the Eq. (17) in a matrix form as

$\overrightarrow{\boldsymbol{d}}=\frac{\alpha_{1} B_{\mathrm{gi}} \mu_{\mathrm{gi}}}{2 \pi K_{\mathrm{g}} h}\left(\boldsymbol{F}+\boldsymbol{D}_{\mathrm{s}}\right) \overrightarrow{\boldsymbol{q}}_{\mathrm{sc}}$

There are two basic vectors in the Eq. (18): the pressure drop vector $\overrightarrow{\boldsymbol{d}}$ and the production vector $\overrightarrow{\boldsymbol{q}}_{\mathrm{sc}}$.

$\overrightarrow{\boldsymbol{d}}=\left[\begin{array}{l}d_{1} \\ d_{2} \\ \vdots \\ d_{n}\end{array}\right]=\left[\begin{array}{l}\bar{P}_{\mathrm{p}}-P_{\mathrm{pwf}, 1} \\ \bar{P}_{\mathrm{p}}-P_{\mathrm{pwf}, 2} \\ \vdots \\ \bar{P}_{\mathrm{p}}-P_{\mathrm{pwf}, n}\end{array}\right], \quad \overrightarrow{\boldsymbol{q}}_{\mathrm{sc}}=\left[\begin{array}{l}q_{\mathrm{sc} 1} \\ q_{\mathrm{sc} 2} \\ \vdots \\ q_{\mathrm{sc} n}\end{array}\right]$.

The influence function matrix $\boldsymbol{F}$ and the diagonal matrix $\boldsymbol{D}_{\mathrm{s}}$ are shown in the Eq. (20).

$\boldsymbol{F}=\left[\begin{array}{llll}F_{11} & F_{12} & \cdots & F_{1 \mathrm{n}} \\ F_{21} & F_{22} & \cdots & F_{2 \mathrm{n}} \\ \vdots & & \\ F_{\mathrm{n} 1} & F_{\mathrm{n} 2} & \cdots & F_{\mathrm{nn}}\end{array}\right], \quad \boldsymbol{D}_{\mathrm{s}}=\left[\begin{array}{llll}s_{1} & 0 & \cdots & 0 \\ 0 & s_{2} & \cdots & 0 \\ \vdots & & \\ 0 & 0 & \cdots & s_{\mathrm{n}}\end{array}\right]$.

Rewrite the Eq. (18), we can get

$\overrightarrow{\boldsymbol{q}}_{\mathrm{sc}}=\frac{2 \pi K_{\mathrm{g}} h}{\alpha_{1} B_{\mathrm{gi}} \mu_{\mathrm{gi}}}\left(\boldsymbol{F}+\boldsymbol{D}_{\mathrm{s}}\right)^{-1} \overrightarrow{\boldsymbol{d}}$

Define the quasi-steady stateless dimension production index:

$J_{\mathrm{Dj}}=\frac{\alpha_{1} q_{\mathrm{scj}}(t) B_{\mathrm{gi}} \mu_{\mathrm{gi}}}{2 \pi K_{\mathrm{g}} h\left[\bar{P}_{p}(t)-p_{\mathrm{pwf}}\right]}$

Combining the Eqs. (21) and (22), we can get 
$\left\{\begin{array}{l}1=J_{\mathrm{D} 1}\left[F_{1}\left(y_{\mathrm{w} 1}\right)+s_{1}\right]+J_{\mathrm{D} 2} F_{2}\left(y_{\mathrm{w} 1}\right)+\cdots+J_{\mathrm{DN}} F_{\mathrm{N}}\left(y_{\mathrm{w} 1}\right) \\ 1=J_{\mathrm{D} 1} F_{1}\left(y_{\mathrm{w} 2}\right)+J_{\mathrm{D} 2}\left[F_{2}\left(y_{\mathrm{w} 2}\right)+s_{2}\right]+\cdots+J_{\mathrm{DN}} F_{\mathrm{N}}\left(y_{\mathrm{w} 2}\right) \\ \cdots \\ 1=J_{\mathrm{D} 1} F_{1}\left(y_{\mathrm{wn}}\right)+J_{\mathrm{D} 2} F_{2}\left(y_{\mathrm{wn}}\right)+\cdots+J_{\mathrm{DN}}\left[F_{\mathrm{n}}\left(y_{\mathrm{wn}}\right)+s_{\mathrm{n}}\right]\end{array}\right.$.

By combining the Eqs. (13) and (23), and by following the operation of 'three step method', the transient productivity of the gas reservoirs can be obtained.

The 'three step method' is present as the following:

Step 1 The required data, such as reservoir size and well location coordinates are collected, and then according to the Eq. (13), the influence function can be obtained.

Step 2 The Eq. (23) is solved by Gauss method, and the dimensionless production index of each well is obtained.

Step 3 By substitute the dimensionless production index of each well into the Eq. (22), the production of each well $f\left(n, q_{\mathrm{k}}\right)$ is obtained.

Whether it is a regular well pattern or an irregular well pattern, the production of the gas wells after well pattern infilling technology can be obtained.

\section{Average production}

In the actual gas reservoir development, it is often required to take the average production of a single well for a period of time, which is used for gas well dynamic analysis and production evaluation. Therefore, it is necessary to give a calculation model of average production by being based on formula (23).

The average pressure drop rate is

$\frac{\mathrm{d} \bar{P}_{\mathrm{p}}}{\mathrm{d} t}=-\frac{\alpha_{2} \sum_{j=1}^{n} q_{\mathrm{scj}}(t) B_{\mathrm{gi}}}{A h \varphi c_{\mathrm{gi}}}$,

where $\alpha_{2}$ is the unit conversion factor, and in the SI unit system (Chen 1988), $\alpha_{2}$ is 0.04167 .

Substitute the Eq. (22) in (24), we can get

$\frac{\mathrm{d} \bar{P}_{\mathrm{p}}}{\mathrm{d} t}=-c_{1} \bar{P}_{\mathrm{p}}+c_{2}$,

where

$c_{1}=\frac{\alpha_{2} 2 \pi K_{\mathrm{g}} \sum_{j=1}^{n} J_{\mathrm{Dj}}}{\alpha_{1} A \varphi c_{\mathrm{gi}} \mu_{\mathrm{gi}}}, \quad c_{2}=\frac{\alpha_{2} 2 \pi K_{\mathrm{g}} \sum_{j=1}^{n} J_{\mathrm{Dj}} P_{\mathrm{pwf}}}{\alpha_{1} A \varphi c_{\mathrm{gi}} \mu_{\mathrm{gi}}}$.

Solve the Eq. (26), and the average pressure is obtained as the following:

$\bar{P}_{\mathrm{p}}=\frac{c_{2}}{c_{1}}+\left(P_{\mathrm{pi}}-\frac{c_{2}}{c_{1}}\right) \mathrm{e}^{-c_{1} t}$.
By combining the Eqs. (22), (26) and (27), the average production $\bar{f}\left(n, q_{\mathrm{k}}\right)$ can be obtained.

\section{Well pattern density determination}

Due to the low natural productivity of low-permeability gas reservoirs and the large seepage resistance of reservoir fluids, the reasonable well pattern density is the key to the success of developing low-permeability gas fields. The economic benefits, cumulative production, and the number of wells have optimal values by considering economic factors, such as gas prices and drilling and completion costs. Through these optimal values, the reasonable well pattern density and limit well pattern density can be determined.

Here, take the average production $\bar{f}\left(n, q_{\mathrm{k}}\right)$ as an example to show how to determine the well pattern density.

When there are $n$ wells producing in the gas reservoir at the same time, the total sales income $V_{1}$ can be obtained by the Eq. (28).

$$
\begin{aligned}
V_{1}= & C t \sum_{k=1}^{n} \bar{f}\left(n, q_{\mathrm{k}}\right)\left[1+(1+j)+(1+j)^{2}\right. \\
& \left.+\cdots(1+j)^{t-1}\right]=C t \sum_{k=1}^{n} \bar{f}\left(n, q_{\mathrm{k}}\right)\left[\frac{(1+j)^{t}-1}{j}\right],
\end{aligned}
$$

where $C$ is the price of natural gas, yuan/ton. $j$ is the discount rate, decimal.

The total development investment $V_{2}$ can be obtained by the Eq. (29).

$V_{2}=n M\left[1+(1+j) j+(1+j)^{2} j+\cdots+(1+j)^{t-2} j\right]=n M(1+j)^{t-1}$,

where $M$ is the total investment for each well, yuan/well.

The total cost of development and maintenance management $V_{3}$ can be obtained by the Eq. (30).

$V_{3}=n G\left[1+(1+j)+(1+j)^{2}+\ldots+(1+j)^{t-1}\right]=n G\left[\frac{(1+j)^{t}-1}{j}\right]$,

where $G$ is the single well maintenance management fee, yuan / ton.

The net income $V$ can be obtained by the Eq. (31).

$V=V_{1}-V_{2}-V_{3}$

when $V=0$, the limit well number $n_{\mathrm{jx}}$ under the current conditions is obtained, and the ultimate well pattern density is obtained.

When $\mathrm{d} V / \mathrm{d} n=0$, that is to solve the Eq. (32)

$C t \sum_{k=1}^{n} \overline{f^{\prime}}\left(n, q_{\mathrm{k}}\right)\left[\frac{(1+j)^{t}-1}{j}\right]=M(1+j)^{t-1}+G\left[\frac{(1+j)^{t}-1}{j}\right]$. 


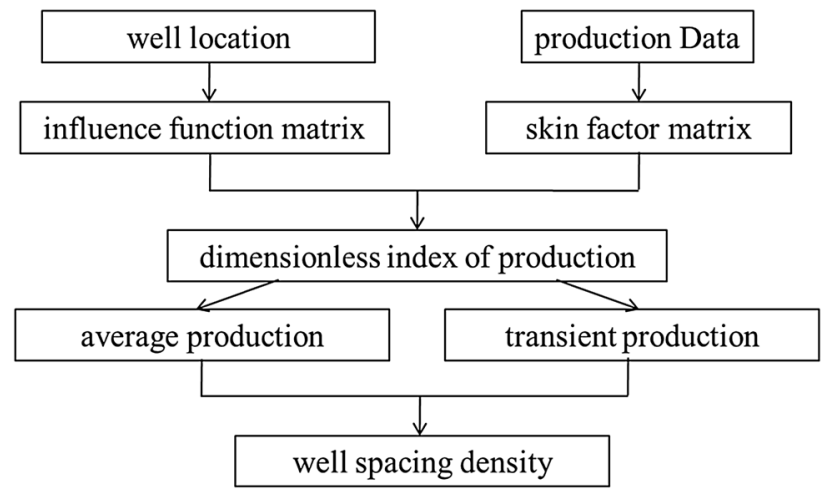

Fig. 2 The calculation diagram of the well spacing density

The reasonable number of wells $n_{\mathrm{hl}}$ under current conditions can be obtained, and the reasonable well pattern density can be obtained.

The Eq. (32) is a method for determining the well pattern density, which is based on the dynamic analysis of gas wells in low-permeability gas reservoirs. Using this method, the number of production wells can be adjusted according to the production dynamics of low-permeability gas reservoirs, which can realize efficient and stable development of lowpermeability gas reservoirs. The specific calculation steps are shown in Fig. 2.

According to Serkachev's formula (Yikun and Liang 2010), there is a certain relationship between well pattern density and gas recovery. Being based on the dynamic production rate of single well, the gas recovery can be obtained by the Eq. (33)

$E_{\mathrm{R}}=\frac{t \sum_{k=1}^{n} \bar{f}\left(n, q_{\mathrm{k}}\right)}{N} \times 100 \%$,

where $E_{\mathrm{R}}$ is the gas recovery, $\% . N$ is the geological reserves, $\mathrm{m}^{3}$.

Through the formula (33), the gas recovery rate under the economical or reasonable well pattern density can be obtained.
Table 2 The Coordinates of well position and skin factor

\begin{tabular}{lll}
\hline Time & Coordinates & Skin factor \\
\hline$t=0 \mathrm{~d}$ & $\left(x_{1}, y_{1}\right)=(896.13 \mathrm{~m}, 1407.96 \mathrm{~m})$ & $s_{1}=9.1$ \\
& $\left(x_{2}, y_{2}\right)=(2816.37 \mathrm{~m}, 1408.14 \mathrm{~m})$ & $s_{2}=0.3$ \\
$t=100 \mathrm{~d}$ & $\left(x_{3}, y_{3}\right)=(2048.23 \mathrm{~m}, 640.08 \mathrm{~m})$ & $s_{3}=-2.7$ \\
\hline
\end{tabular}

\section{Case analysis}

The temperature of a rectangular sealed gas reservoir remains unchanged $(T=361 \mathrm{~K})$. The reservoir and fluid characteristics are shown in Table 1.

In the initial stage, there were two production wells. When the production time was 100 days, an infill well was added. The well parameters are shown in Table 2.

When $t=100$ days, the influence function matrix and the skin factor matrix are shown as below.

$\boldsymbol{F}=\left[\begin{array}{ll}9.61877 & -1.13693 \\ -1.13693 & 9.41553\end{array}\right], \quad \boldsymbol{D}_{s}=\left[\begin{array}{ll}9.1 & 0 \\ 0 & 0.3\end{array}\right]$.

Substitute (34) in (21), the dimensionless production index can be obtained.

$J_{\mathrm{D} 1}=0.052551, \quad J_{\mathrm{D} 2}=0.093237$.

When $t=100$ days, the average reservoir pressure is $7.07 \mathrm{MPa}$, and using Eq. (19), the production can be obtained, shown as below:

$q_{1}=4.18 \times 10^{6} \mathrm{~m}^{3} /$ day, $\quad q_{2}=7.82 \times 10^{6} \mathrm{~m}^{3} /$ day.

When $t=500$ days, the influence function matrix and the skin factor matrix are shown as below.

$\begin{aligned} \boldsymbol{F} & =\left[\begin{array}{lll}9.61877 & -1.13693 & -0.44266 \\ -1.13693 & 9.41553 & -0.05773 \\ -0.44261 & -0.05769 & 8.64801\end{array}\right], \\ \boldsymbol{D}_{s} & =\left[\begin{array}{lll}9.1 & 0 & 0 \\ 0 & 0.3 & 0 \\ 0 & 0 & -2.7\end{array}\right]\end{aligned}$
Table 1 Gas reservoir parameters for the example 1

\begin{tabular}{llll}
\hline Parameter & Values & Parameter & Values \\
\hline Reservoir length & $x_{\mathrm{e}}=4061.6 \mathrm{~m}$ & Volume factor & $B_{\mathrm{gi}}=0.0053$ \\
Reservoir width & $y_{\mathrm{e}}=1020.2 \mathrm{~m}$ & Compression coefficient & $c_{\mathrm{gi}}=0.0413 \mathrm{MPa}^{-1}$ \\
Reservoir height & $h=11.43 \mathrm{~m}$ & Wellbore radius & $r_{\mathrm{w}}=0.0831 \mathrm{~m}$ \\
Temperature & $T=361 \mathrm{~K}$ & Original pressure & $p_{\mathrm{i}}=18.6201 \mathrm{MPa}$ \\
Permeability & $k_{\mathrm{gi}}=0.11 \mu \mathrm{m}^{2}$ & Bottom hole flowing pressure & $p_{\mathrm{wf}}=6.2051 \mathrm{MPa}$ \\
Porosity & $\varphi=0.14$ & Viscosity & $\mu_{\mathrm{gi}}=0.0241 \mathrm{cp}$ \\
Gas saturation & $S_{\mathrm{g}}=51 \%$ & Effective area & $A=2.03 \mathrm{~km}^{2}$ \\
\hline
\end{tabular}




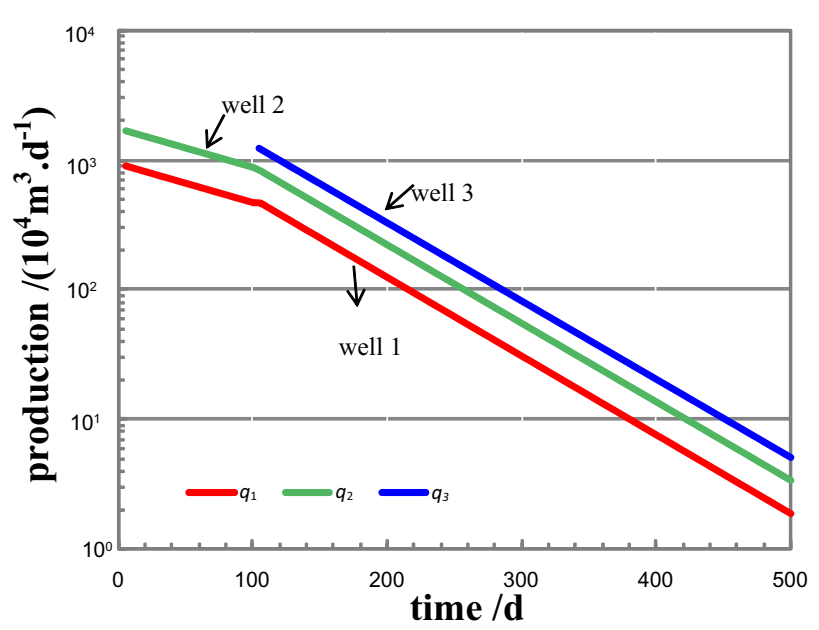

Fig. 3 The curves of flow rate versus time

Substitute (35) in (21), the dimensionless production index can be obtained.

$J_{\mathrm{D} 1}=0.052551, \quad J_{\mathrm{D} 2}=0.093237, \quad J_{\mathrm{D} 3}=0.14099$.

When $t=500$ days, the average reservoir pressure is $6.36 \mathrm{MPa}$, and using Eq. (19), the production can be obtained, shown as below:

$q_{1}=1.7038 \times 10^{4} \mathrm{~m}^{3} /$ day, $\quad q_{2}=3.0229 \times 10^{4} \mathrm{~m}^{3} /$ day,

$q_{3}=4.5713 \times 10^{4} \mathrm{~m}^{3} /$ day.

In the same way, the other time step production can be obtained, as shown in Fig. 3.

Figure 3 shows that when the production time is 100 days, the production deceleration rate of well 1 and well 2

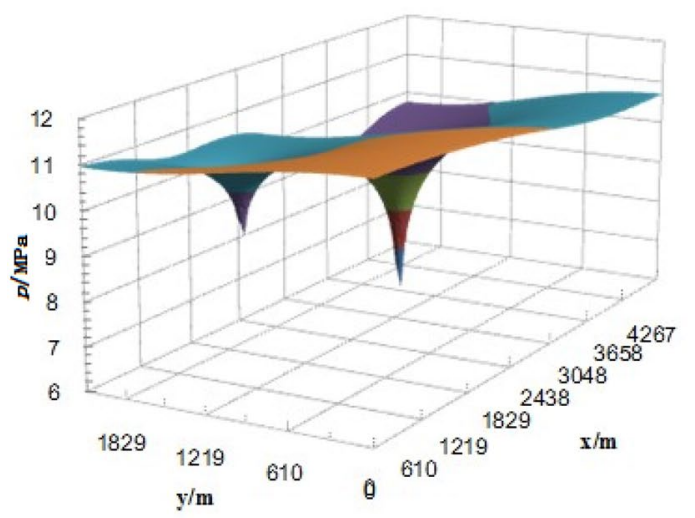

(a) $t=100 \mathrm{~d}$ changes, and the deceleration rate increases, which is caused by the mutual influence of pressure as the infill (well 3 ) is producing. In the quasi-steady state, if there is no other infill well, the production deceleration rate is a fixed value.

The pressure distribution at 100 and 500 days is shown in Fig. 4. Figure 4 shows that the new infill well will aggravate formation energy depletion, and it is necessary to replenish energy to the formation under the premise of ensuring production.

\section{Sensitivity analysis}

\section{Production}

Through calculation, the relationship between production $(q)$, cumulative production $(Q)$, and the number of wells $(n)$ is obtained, as shown in Fig. 5.

Figure 5 shows that as the number of wells increases, the production first increases and then decreases. When the number of wells is the same, the initial production increases rapidly, and after reaching the peak value, the production is slowly reduced. This makes the cumulative production increase in the early stage. When the number of wells exceeds the number of reasonable production wells, the cumulative output gradually becomes flat. Therefore, there is a reasonable well pattern density (reasonable number of wells) in the development of the gas reservoir. When exceeding the reasonable number of wells, the cumulative production tends to be stable and the economic benefits reduce.

\section{Gas recovery}

Substitute the calculated cumulative production at different production time in Eq. (33), and the relationship between gas recovery and well pattern density can be obtained, as

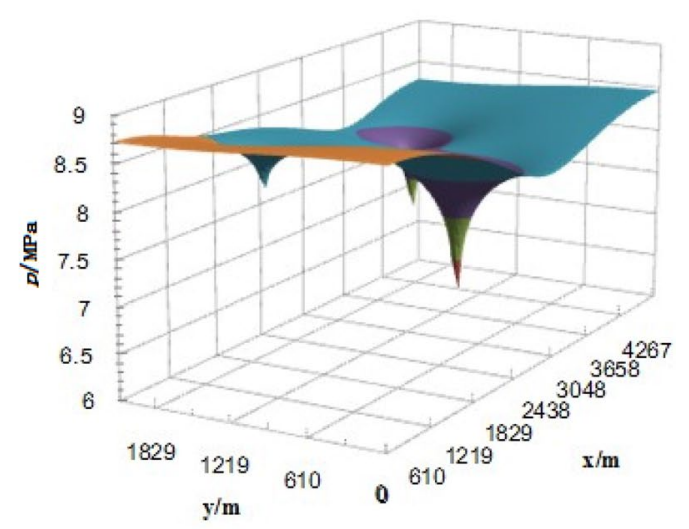

(b) $t=500 \mathrm{~d}$

Fig. 4 The pressure distribution at 100 and 500 days 

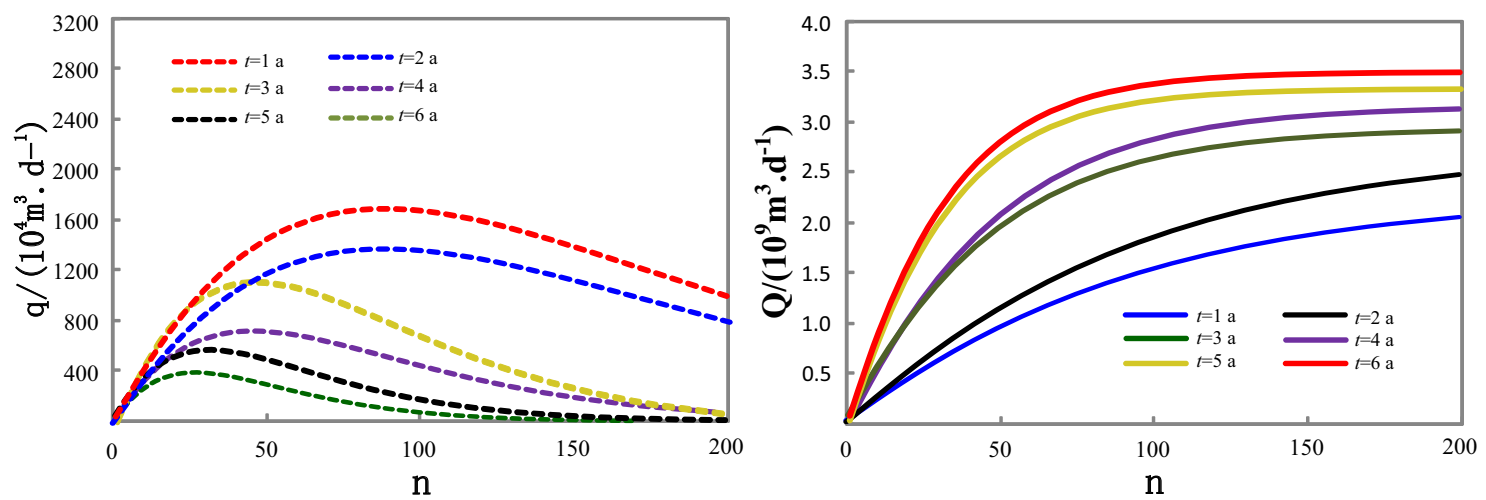

Fig. 5 The curves of flow rate and cumulative production versus well number

shown in Fig. 6. Figure 6 shows that as the density of the well pattern decreases, the gas recovery rate increases. When the well pattern density is $45-60 \mathrm{~km}^{2} /$ well, the increase rate of the gas recovery is not obvious. Because the controllable reserves of a single well are certain. When the well pattern density exceeds the technical limit well density of a single well, it is usually not used to reduce the well spacing to improve gas recovery. When it is compared with the Sherka's empirical formula, the trend of this model in the paper is generally the same, except that the nodes and amplitudes of the curve rise are different.

\section{Gas price}

The gas price $C$ is $1.0,1.5,2.0,2.5,3.0,3.5$ yuan $/ \mathrm{m}^{3}$, and the reasonable number of wells in the low-permeability gas reservoir is calculated, as shown in Fig. 7. Figure 7 shows

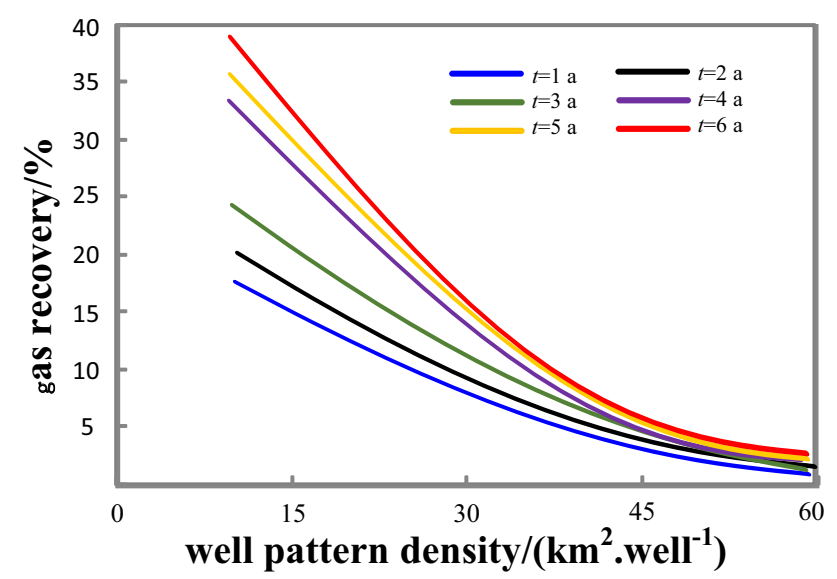

Fig. 6 The curves of gas recovery and well pattern density versus time

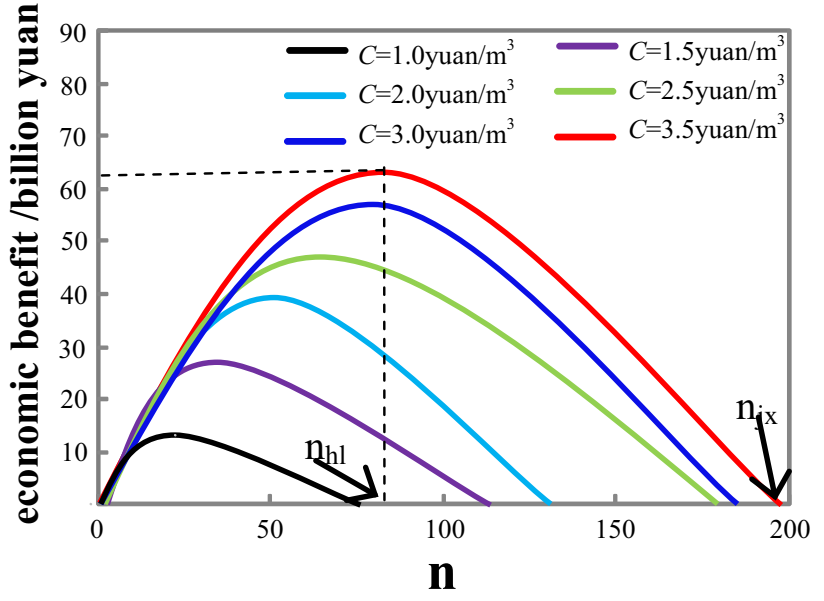

Fig. 7 The curves of cumulative production and economic benefits versus time

that when the gas price is $3.5 \mathrm{yuan} / \mathrm{m}^{3}$, the reasonable number of wells in the gas reservoir is 84 , and the number of economic limit wells is 193 . The calculated reasonable well pattern density is $20.28 \mathrm{well} / \mathrm{km}^{2}$, and the economic limit well density is $46.61 \mathrm{well} / \mathrm{km}^{2}$.

\section{Physical parameter}

By changing the effective thickness and the original permeability of the gas reservoir, the reasonable well pattern density under different physical conditions is studied, and a reasonable well pattern density is obtained, as shown in Fig. 8. Figure 8 shows that when the effective thickness of the reservoir is small, the reasonable well pattern density has a linear relationship with effective thickness. After the inflection point, the reasonable well pattern density increases 


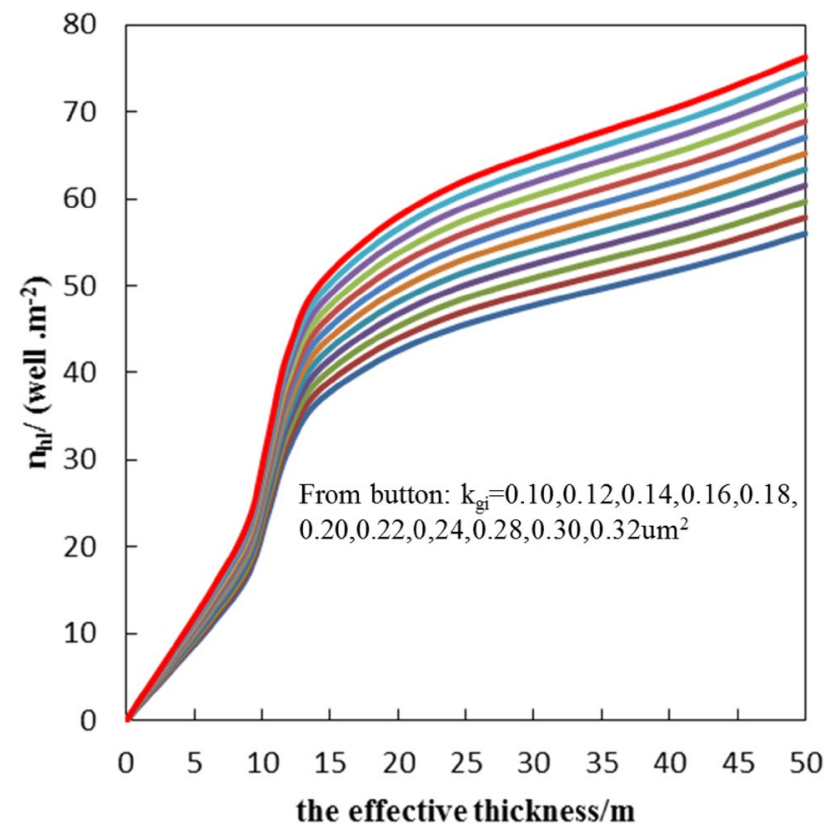

Fig. 8 The curve of reasonable well spacing density in different physical properties

fast first and then increases slowly. For the same reservoir thickness, as the original permeability increases, the reasonable well pattern density also increases.

\section{Methods comparison}

The method is compared with the empirical formula method (Cunyou and Haibo 2010), the net present value method (Mengkun et al. 2012), the numerical simulation method (Yikun and Liang 2010), and the actual data. The comparison results are shown in Table 3. Table 3 shows that the calculation results of this method in this paper and the numerical simulation method are very close, but this method is much closer to the actual data, which indicates that this method in this paper is reliable. The calculation results of the net present value method are generally lower than the method of this paper, mainly because the net present value method does not consider the influence of cross-well interference and skin factor on single well productivity, and ignores the ratio of injection-production wells to recovery. When the same recovery is achieved, more infill wells are needed for the net present value method. In the middle and late stages of low-permeability gas reservoir development, due to the comprehensive production data, the calculation error of empirical formula method is reduced. From the perspective of economy and time saving, the method in this paper is the best solution to obtain reasonable well pattern density.

\section{Conclusion}

1. At present, there are two kinds of ways to determine the well pattern density, namely gas reservoir engineering and numerical simulation. The gas reservoir engineering method is mainly based on the empirical formula of Serkachev's formula, and it is not suitable for lowpermeability gas reservoirs with low porosity and low permeability characteristics, and it does not consider the pressure-sensitive effect. The numerical simulation method needs to combine geological model, and it takes a long time to obtain the well pattern density. For the numerical simulation method, the corresponding model should be built based on the research area, which cannot be universal. In this paper, a new method to determine the economical and reasonable well pattern density based on dynamic production of low-permeability gas reservoirs is established. This method can adjust the number of production wells according to the production dynamics, and provide a theoretical basis for the reorganization of the old gas field well pattern and the design of the new gas field well pattern.

2. When the infilling wells are producing, the formation energy consumption increases, and the production deceleration rate of the old wells are different before and after well pattern infilling. To maintain the efficient and stable development of the low-permeability gas reservoir, energy must be added to the formation, such as water injection and gas injection.

3. With the number of production wells changing, the economic benefit and cumulative production have the maximum value. Under the same reservoir physical property, the reasonable well pattern density increases with the increase of natural gas price. Under the same natural gas price, the reasonable well pattern density increases
Table 3 comparison table of calculation results using different ways $\left(\mathrm{km}^{2} /\right.$ well $)$

\begin{tabular}{llllll}
\hline Time/a & $\begin{array}{l}\text { Empirical for- } \\
\text { mula method }\end{array}$ & $\begin{array}{l}\text { Net present value } \\
\text { method }\end{array}$ & $\begin{array}{l}\text { Numerical simula- } \\
\text { tion method }\end{array}$ & $\begin{array}{l}\text { This method in } \\
\text { this paper }\end{array}$ & Actual data \\
\hline 1 & 32.61 & 18.64 & 21.47 & 20.28 & 20.01 \\
3 & 25.43 & 16.29 & 19.86 & 18.72 & 18.91 \\
5 & 18.03 & 15.05 & 17.92 & 17.26 & 17.19 \\
7 & 16.99 & 14.82 & 16.63 & 16.05 & 16.11 \\
\hline
\end{tabular}


with the increase of reservoir permeability and effective thickness, and decreases with the increase of recovery factor. The method is a simple and reliable method for determining the economical and reasonable well pattern density.

Open Access This article is distributed under the terms of the Creative Commons Attribution 4.0 International License (http://creativeco mmons.org/licenses/by/4.0/), which permits unrestricted use, distribution, and reproduction in any medium, provided you give appropriate credit to the original author(s) and the source, provide a link to the Creative Commons license, and indicate if changes were made.

\section{References}

Awotunde AA (2014) Well placement optimization constrained to minimum well spacing. SPE169272

Bowers B (1981) Gas reservoir performance monitoring. PETSOC Conference Paper 30504, pp 781-790

Changmin ZHANG, Xiaoqing WU (2012) A new method for establishing well spacing density. Chongqing Univ Sci Technol 14(3):76-78

Chen YQ (1988) Reservoir engineering commonly used formula using different practical system of units. Petrol Explor Dev 22(1):69-76

Cunyou Z, Haibo S (2010) A method to establish the relationship between recovery efficiency and well spacing density. Petrol Geol Recovery Eff 17(4):43-47

Fenglian Z, Yuting C, Zhen G (2008) How to identify rational and ultimate well spacing density for low permeability reservoir. Petrol Geol Oilfield Dev Daqing 27(2):88-90

Hongbing J, Yang L (2013) A method to calculate reasonable well pattern density for oilfield. J Oil Gas Technol 35(4):122-128

Hong-ge J (2014) A new calculation method of economic limit well pattern density. Oil Gas Field Surf Eng 33(2):30-31

Hongwei X, Shicheng T (2010) The encrypted adjustment of reasonable and practical well pattern density for old oilfields. J Oil Gas Technol 32(1):318-320
Jian X, Yongqiang Hu, Zhen C et al (2013) Dynamic prediction model for low permeability gas reservoir taking the real gas into account. J Northeast Petrol Univ 37(2):91-95

Jinshan H (2013) A new method of economic limit well pattern density calculation in oil fields. Petrol Geol Recovery Eff 20(3):53-55

John UM (2010) Non-linear programming for well space optimization of oil reservoirs. SPE140674

John MPU (2011) A stochastic approach to well spacing optimization of oil reservoirs. SPE150736

Kale D, Mattar L (2004) Solution of a non-linear gas flow equation by the perturbation technique. J Cryst Process Technol 51(6):63-67

Krisanne LE, Weissert S, Jachson J et al (2011) Marcellus shale hydraulic fracturing and optimal well spacing to maximize recovery and control cost. SPE140463

Lalehrokh F, Bouma J (2014) Well spacing optimization in eagle ford. PE171640

Mengkun R, Yuping Z, Li H et al (2012). The calculation of economic reasonable well pattern density. Oil Gas Field Surf Eng 31(3):38-39

Peres AMM, Serra KV, Reynolds AC (2008). Toward a unified theory of well testing for nonlinear-radial-flowproblems with application to interference tests. SPE 18113

Quanlin W, Shichao C, Zili C et al (2012) Determination of reasonable well spacing in low permeability reservoir based on two phase flow. J Northeast Petrole Univ 36(4):45-48

Song L, Jingkun J, Hang Y (2014) Well pattern calculation method based on economic limit in old oilfields using well spacing and well-controlled reserves. PGRE 21(4):104-106

Thompson L, Reynolds A (2009) Analysis of variable-rate well-test pressure data using Duhamel's principle. SPE Paper 13080

Wu Y-S (2012) Transient gas flow in unconventional gas reservoir. SPE 154448

Yikun L, Liang W, Fulin W (2010) The application of numerical simulation technology in tower 4 Oilfield well pattern adjustment. Lithol Reserv 22(1):119-121

Publisher's Note Springer Nature remains neutral with regard to jurisdictional claims in published maps and institutional affiliations. 